ИССЛЕДОВАНИЕ ЗАВИСИМОСТИ ПОЯВЛЕНИЯ АНОМАЛЬНО ЯРКИХ МЕЗОСФЕРНЫХ ОБЛАЧНЫХ ОБРАЗОВАНИЙ ОТ МАСШТАБНЫХ КОСМИЧЕСКИХ ЯВЛЕНИЙ

\author{
А. С. Найдёнова \\ Уральский федеральный университет
}

Феномен серебристых облаков (СО), облаков, образующихся на высотах 70-95 км в мезосфере, до сих пор остается не до конца изученным. На сегодняшний день существует несколько гипотез их образования. Цель данной работы - проверка некоторых гипотез образования серебристых облаков (извержение вулканов, максимум метеорных потоков). Из вулканов были проанализированы Эйяфьядлайёкюдль (Исландия) и вулканы Камчатки. Также были рассмотрены метеорные потоки Квадрантиды, Лириды, Ариетиды и их максимумы активности. Выявлено соответствие максимума метеорных потоков появлению локальных увеличений количества и яркости этих образований.

\title{
RESEARCH OF DEPENDENCE OF APPEARANCE OF ABNORMALLY BRIGHT MESOSPHERIC CLOUDS STRUCTURES ON LARGE-SCALE SPACE PHENOMENA
}

\author{
A. S. Naidenova \\ Ural Federal University
}

The phenomenon of noctilucent clouds (NC), i. e. clouds that form at an altitude of $70-95 \mathrm{~km}$ in the mesosphere, is still not fully understood. To date, there are several hypotheses explaining the formation of these clouds. The goal of this work was to test some hypotheses of the formation of noctilucent cloud, namely, volcanic eruptions and maxima of meteor showers. I analyzed Eyyafyadlayokyudl (Iceland) volcano and the volcanoes of Kamchatka. The meteor showers Quadrantids, Lyrids, Arietids and their activity maxima were also considered. The correspondence between the maxima of meteor showers and local enhancements in the number and brightness of noctilucent clouds is revealed.

(C) Найдёнова А. С., 2020 
Были рассмотрены некоторые события: извержения вулкана Эйяфьядлайёкюдль (Исландия), вулканы Камчатки; максимумы метеорных потоков: Квадрантиды, Лириды, Ариетиды, с которыми я хотела связать появление аномально ярких СО, но столкнулась с проблемой недостатка данных и отсутствия наблюдений. Сложность исследования мезосферных облаков в южном полушарии заключается и в географическом положении материков (на нужной широте почти нет суши, с которой могло бы наблюдаться явление), поэтому наблюдения осуществимы только со спутников LIDAR. Для того чтобы увидеть CO, необходимо совмещение многих факторов: чистое небо, наличие навигационных сумерек, угол погружения Солнца под горизонт 6-12 ${ }^{\circ}$ Вулканический пепел иногда относит на регионы, в которых в период наблюдения СО наблюдаются полярный день или белые ночи, а высота выбросов пепла может не достигать необходимой высоты или быть незначительной концентрации. Также наблюдались метеорологические условия, которые препятствовали выполнению условия «ясное небо» для наблюдения СО. Поэтому мне не удалось проследить связь между извержениями исследуемых вулканов и появлением СО. Для исследования связи метеорных потоков с появлением СО я использовала информацию о потоках и наблюдении СО, взятую из соответствующих архивов [1] (см. таблицу). В результате были найдены локальные увеличения количества и яркости этих образований.

\section{АРХИВ НАБЛЮДЕНИЙ СЕРЕБРИСТЫХ ОБЛАКОВ}

\begin{tabular}{|c|c|c|c|c|c|c|c|c|c|c|c|c|}
\hline \multirow[b]{2}{*}{ № } & \multicolumn{4}{|c|}{ Отчеты о на5.люденіях е періода с 2011-06-01 UT 02 OO } & \multicolumn{3}{|c|}{$r: 02011-06-12 \cup T 0200$} & \multicolumn{3}{|c|}{ 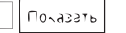 } & \multirow[b]{2}{*}{ Lonr. } & \multirow[b]{2}{*}{ Oér. } \\
\hline & HaSnnoatens & $\begin{array}{l}\text { UT mavano } \\
\text { raśnמsemu:" }\end{array}$ & $\begin{array}{l}\text { UT korel } \\
\text { raśncaerbií }\end{array}$ & $\begin{array}{c}\text { Kon. } \\
\text { afnakoe }\end{array}$ & $\begin{array}{l}\text { CODMB } \\
\text { OGNaKOB }\end{array}$ & 9DKOCTB & $\begin{array}{l}\text { He.s. } \\
\text { O6pas. }\end{array}$ & A3. & Boc. & $\Delta n D$. & & \\
\hline 107 & $\begin{array}{l}\text { Unprepu:nos } \\
\text { Erod }\end{array}$ & $\begin{array}{c}2011.06 .09 \\
21: 15: 00\end{array}$ & $\begin{array}{c}2011.06 .09 \\
22: 15: 00\end{array}$ & $70 \%$ & $\begin{array}{l}\text { I; } 110 ; 116 ; \\
\text { IIIa; }\end{array}$ & $3 i 5$ & $5 / 10$ & $0^{\circ}$ & $75^{2}$ & S4. 58 & 39.96 & $10 \%$ \\
\hline
\end{tabular}

Отчет о наблюдениях СО в период (01.06-12.06 за 2011 г.) активности метеорного потока Ариетиды

Автор выражает благодарность К. И. Смирновой и О. С. Угольникову.

\section{Библиографические ссылки}

1. Архив наблюдений серебристых облаков. - http://meteoweb.ru/ astro/nlc/reports.php. (accessed: 22.05.2019). 